\title{
Studies on Urea=Nitrogen Concentration of the Blood.
}

Part. II.

The Effect of Caffeine on the Blood Urea-Nitrogen Concentration.

By

KASANU TASHIRO.

(田 代 重)

(From the Laboratory of Prof. T. Kato's Medical Clinic, Tohoku Imperial University, Sendai, Japan.)

Caffeine and its derivatives are usually used as diuretics for various renal diseases, in which the urea and non-protein nitrogen cencentrations are often accumulated in the blood. Evidence that during caffeine diuresis urea excretion in the urine is increased was put forwards by Sch roeder, ${ }^{1}$ Anten and others, but what effect caffeine would have on the blood urea content seems not to have been sufficiently studied. Only $Z$ anda, in his investigation on the actions of caffeine upon the time of coagulation, the viscosity and the urea concentration of the blood in dogs, asserted that after the administration of this drug, the urea content of the blood was actually increased. If urea in the blood really is augmented by caffeine, it becomes a serious question whether caffeine should be used as a treatment for renal diseases, which are accompanied by the accumulation of urea and residual nitrogen in the blood. I experimented first to ascertain what changes the blood urea-nitrogen concentration would undergo if caffeine be given to an animal.

The animals subjected to the experiments, as stated in Part I, had their large auricular nerves and cervical sympathetics on both sides previously cut and were neither bound nor anrsthetized. In Exp. I, 20 minutes after injecting $0.05 \mathrm{grm}$. of caffeine, it showed an increase in the blood urea-nitrogen concentration of about $57 \%$, then making a gradual decrease until it almost recovered its original ralue in 3 hours. In Exp. II, the same

1) Schroeder, Arch. f. exper. Pathol. u. Pharm, 1857, 24, 55.

2) Anten, Arch. intem. de Pharmacodyn., $19018,1$.

3) Zanda, Arch. ital. de Biol., 1907, 47, 299 ; cit. by Bock in Heffter' Handb. exper. Pharmakol, Leipzig 1923, II-1, 526. 
Exp. I. May 8, 1922. Rabbit \&. Body weight 1.8 kilos.

\begin{tabular}{|c|c|c|}
\hline Time & Urea-N (mgrm $\%)$ & Remarks \\
\hline $\begin{array}{l}11^{32} \\
11^{36} \\
11^{55} \\
12^{20} \\
1^{25} \\
2^{25}\end{array}$ & $\begin{array}{l}21.0 \\
33.0 \\
25.2 \\
25.9 \\
21.7\end{array}$ & 5 c.c. $1 \%$ caffeine subcutaneously injected. \\
\hline
\end{tabular}

Exp. II. May 1, 1923. Rabbit 3. Body weight 1.6 kilos.

\begin{tabular}{l|c|c}
\hline Tine & Urea-N (mgrm 06$)$ & Remarks \\
\hline $3^{40}$ & 23.8 & \\
$3^{45}$ & 26.6 & 5 c.c. 10.0 caffeine subcutaneously injected. \\
$3^{55}$ & 30.8 & \\
$4^{* 0}$ & 29.4 & \\
$5^{25}$ & 26.6 &
\end{tabular}

Exp. III. April 21, 1923. Rabbit $\hat{o}$. Body weight 1.6 kilos.

\begin{tabular}{l|c|c}
\hline Time & Urea-N (mgrm \%ó) & Remarks \\
\hline $2^{20}$ & 29.4 & \multirow{2}{*}{ 10 c.c. $1 \%$ caffeine subcutaneously injected. } \\
$2^{20}$ & 25.2 & \\
$2^{30}$ & 28.7 & \\
$3^{\circ 0}$ & 27.8 & \\
$3^{\circ 0}$ & 27.3 &
\end{tabular}

Exp. IV. December 26, 1925. Rabbit $\hat{\jmath}$. Body weight 1.7 kilos.

\begin{tabular}{c|c|c}
\hline Time & Urea-N (ngrm 0$)$ & Renarks \\
\hline $10^{20}$ & 19.6 & \\
$10^{25}$ & 12.6 & 7.5 c.c. $20 \%$ caffeine subcutaneously injected. \\
$10^{45}$ & 11.2 & \\
$11^{\circ 0}$ & 15.4 & \\
$1^{4.5}$ & 20.3 & \\
$4^{15}$ & &
\end{tabular}

amount of caffeine was injected with the result that the blond urea-nitrogen concentration was slightly increased in ten minutes, the most significant increase being noticed 30 minutes later. Other experiment, not described here, with the same amount of caffeine injected, also showed the same results. When $0.05 \mathrm{grm}$. of caffeine was injected into a rabbit of 2 kilos body weight the blood urea-nitrogen concentration increased in twenty minutes from the original value of $37.8 \mathrm{mgrm}$ \% to $44.8 \mathrm{mgrm}$;ó, and another of 2.1 kilos body weight with a hypo- 
dermical injection of $0.07 \mathrm{grm}$. caffeine given, showed an increase in 15 minutes from 28.7 mgrm of to $33.6 \mathrm{mgrm}$ :'́.

If such amounts of caffeine are given to the rabbits it will be sure to increase the blood urea-nitrogen concentration, but on the contrary, in Exp. III, in which the dose of caffeine has been doubled, the blood urea-nitrogen content reduces to $86 \% \%$ of the original value in 9 minutes, showing no sign of increase during the one hour and ten minutes that have followed. In Exp. IV $0.15 \mathrm{grm}$. of caffeine was given with the result that a marked constriction of the ear ressels was observed, bringing about cyanosis, quick and irregular breathing and agitation, so that taking blood was difficult. The blood urea-nitrogen content was found reduced to $64 \%$ of the original value 20 minutes after the injection, and to $57 \%$ in an hour and 5 minutes, then gradually returning to the original value after about 6 hours. In similar experiments, for instance, a rabbit of 1.6 kilos body weight had $0.1 \mathrm{grm}$. of caffeine injected, and in 18 minutes the original urea-nitrogen value of blood was reduced from $23.8 \mathrm{mgrm} ;{ }^{\prime}$ to $21.0 \mathrm{mgrm} \%{ }^{\circ}$, at the same time causing cyanosis and dyspnoea, which made the further taking of blood impossible, and the animal finally dying after an hour. In another rabbit of 1.9 kilos body weight, into which was injected $0.1 \mathrm{grm}$. of caffeine, the original blood urea-nitrogen value of $39.2 \mathrm{mgrm} \%$ was reduced to $32.2 \mathrm{mgrm}$ $\%$ in 10 minutes, and then gradually recovering, showed $36.4 \mathrm{mgrm} \%$ at the end of two hours.

From these experiments it is generally conceived that in the rabbits with $0.05 \mathrm{grm}$. of caffeine injected, the ear veins become somewhat dilated and the collection of blood is easy, but in others with 0.1 or $0.15 \mathrm{grm}$. of the drug injected, the ear vessels were strikingly contracted, accompanied by marked cyanosis, and more than ten minutes is required for collecting the blood. As to the time for taking blood in such cases, it is recorded in the protocol of experiment when the collection was completed. Some even died before the blood collection was successfully carried out, and some of them that had survived the experiments, died within a few days after.

In short, when a dosis of $0.05 \mathrm{grm}$. of caffeine is injected into a rabbit, the blood urea-nitrogen concentration makes a fairly striking increase, while the dosage of $0.1-0.15 \mathrm{grm}$. is followed by a slight decrease. What I mean here is that decrease or increase does not include the increased elimination of urea through caffeine, so it is not clear whether the process of urea synthesis was accelerated or retarded by caffeine.

Then the following experiments were performed in order to see the changes of blood urea-nitrogen concentration through caffeine and the diuretic effect of the drug in their relations. The rabbits were tied up in a holder which is equipped with an electric warmer, and the abdomen opened. A cannula was inserted into the bladder, the urine drops coming out of it being registered. Another cannulae were inserted into the femoral or carotid artery and the jugular vein, thus preparing for an injection and the collection of blood. No anæsthesia was administered. 
Exp. V. March 20, 1922. Rabbit q. Body weight 2.3 kilos.

\begin{tabular}{|c|c|c|c|}
\hline Time & Drops of urine & Urea-N (mgrm 06$)$ & Remarks \\
\hline 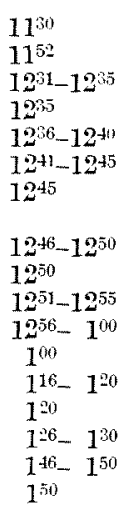 & $\begin{array}{r}1 \\
1 \\
2 \\
\\
155 \\
\\
80 \\
80 \\
40 \\
30 \\
28\end{array}$ & $\begin{array}{l}42.7 \\
42.0 \\
33.6 \\
38.7\end{array}$ & $\begin{array}{l}\text { Tied up and operated. } \\
\text { Operation finished. } \\
5 \text { c.c. } 10 \% \text { caffeine intrarenously } \\
\text { injected. }\end{array}$ \\
\hline
\end{tabular}

Exp. VI. March 24, 1922. Rabbit s. Body weight 1.8 kilos.

\begin{tabular}{|c|c|c|c|}
\hline Time & Drops of urine & Urea-N (mgrm $\left.g^{\prime}\right)$ & Remarks \\
\hline 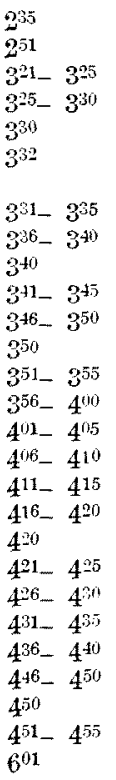 & $\begin{array}{r}4 \\
30 \\
50 \\
51 \\
\\
43 \\
52 \\
36 \\
20 \\
20 \\
15 \\
\\
8 \\
6 \\
5 \\
4 \\
4 \\
\\
2\end{array}$ & $\begin{array}{l}44.8 \\
51.8 \\
51.8\end{array}$ & $\begin{array}{l}\text { Tied up and operated. } \\
\text { Operation finished. } \\
5 \text { c.c. } 1 \% \text { caffeine intravenously } \\
\text { injected. }\end{array}$ \\
\hline
\end{tabular}


Exp. VII. March 17, 1922. Rabbit 1. Body weight 1.9 kilos.

\begin{tabular}{|c|c|c|c|}
\hline Time & Drops of urine & Urea-N (mgrm $\%)$ & Remarks \\
\hline $\begin{array}{l}9^{30} \\
9^{50} \\
10^{26}-10^{30} \\
10^{30} \\
10^{35} \\
10^{31}-10^{45} \\
10^{45} \\
10^{45}-10^{55} \\
10^{55} \\
10^{56}-11^{15} \\
11^{15} \\
11^{16}-11^{35} \\
11^{35} \\
11^{36}-12^{05} \\
12^{45} \\
12^{25}\end{array}$ & $\begin{array}{l}0 \\
0 \\
0 \\
0 \\
0\end{array}$ & $\begin{array}{l}42.9 \\
42.9 \\
42.0 \\
42.0 \\
40.6 \\
47.6\end{array}$ & $\begin{array}{l}\text { Tied up, operated. } \\
\text { Operation finished. } \\
\text { Intravenous injection of } 10 \text { c.c. } \\
1 \% \text { caffeine. }\end{array}$ \\
\hline
\end{tabular}

Exp. VIII. March 21, 1922. Rabbit $\delta$. Body weight 1.3 kilos.

\begin{tabular}{|c|c|c|c|}
\hline Time & Drops of urine & Urea-N (mgrm $\% 0)$ & Remarks \\
\hline $\begin{array}{l}11^{15} \\
11^{58} \\
12^{31}-12^{35} \\
12^{35} \\
12^{36}-12^{40} \\
12^{41}-12^{45} \\
12^{45} \\
12^{46}-12^{50} \\
12^{50} \\
12^{51}-12^{55} \\
12^{56-}-1^{00} \\
1^{60} \\
1^{191}-1^{05} \\
1^{160}-1^{10} \\
1^{11}-1^{15} \\
1^{16-} 1^{50} \\
1^{10} \\
1^{21}-1^{25} \\
1^{30}\end{array}$ & $\begin{array}{r}9 \\
8 \\
8 \\
\\
215 \\
110 \\
60 \\
24 \\
32 \\
8 \\
3 \\
0\end{array}$ & $\begin{array}{l}35.7 \\
37.8\end{array}$ & $\begin{array}{l}\text { Tied up, operated. } \\
\text { Operation finished. } \\
\text { Intrarenous injection of } 8 \text { c.c. } \\
\quad 1 \% \text { caffeine. }\end{array}$ \\
\hline
\end{tabular}

Exp. $V$ shows a striking urine flow brought about by the intravenous injection of 0.05 grm. of caffeine. At the time when the flow was greatest, the blood urea-nitrogen content showed an increase of about 26\%. In Exp. VI the diuretic effect through the same dosis of caffeine was of medium degree, the blood urea-nitrogen concentration increasing about $15 \%$. Other experiments of the same kind yielded the similar results. For instance, when $0.05 \mathrm{grm}$. of caffeine was injected into a rabbit of 1.9 kilos body weight, the urine volume was observed to increase from $2-3$ to $51-62$ drops per minute, and the blood urea-nitrogen content from $46.2 \mathrm{mgrm} \%$ to $56.1 \mathrm{mgrm} \%$, taking a curve similar to that in Exp. VI. Into another rabbit of 1.3 kilos body weight $0.04 \mathrm{grm}$. of caffeine was injected into its vein and though the diuretic effect was not significant, the blood urea-nitrogen content increased 
from 41.3 mgrm \% to $49.0-49.8 \mathrm{mgrm} \%$. Exps. VII and VIII seem to correspond to Exps. III and IV. In Exp. VII, an injection of $0.1 \mathrm{grm}$. of caffeine had no apparent effect on the diuresis and the blood urea-nitrogen content, although a slight increase of the latter was noticed as it was nearing its death. In Exp. VIII $0.08 \mathrm{grm}$. of caffeine was injected into the rein and in spite of the diuretic effect being quite significant, the blood ureanitrogen content did not increase, but rather decreased.

In going over the results of these experiments, what we should be careful to note is that, as described in Part I, the blood urea-nitrogen concentration is affected by the binding. The blood urea-nitrogen contents in Exps. V-VIII, when compared with those of Exps. I-IV, are much higher in their original values, the former being $33.7-44.8 \mathrm{mgrm} \%$ while the latter were $19.6-29.4 \mathrm{mgrm} \%$. In the latter series of experiments it was noticed that the blood urea-nitrogen concentration tended to show a gradual increase near the close of each experiment. These facts may be assumed as the effect of fixation. Consequently it is very difficult to decide the effect of caffeine in Exps. V-VIII. But in Exps. VVI, the blood urea-nitrogen concentration which was increased by the injection of a comparatively small quantity of caffeine, showed a tendency of restoring for a time and again inereasing afterwards. Therefore, we must consider the first increase as that caused by caffeine and the second as the effect coming through binding. In Exps. VII - VIII comparatively large doses of caffeine were given, but the blood urea-nitrogen content did not only show any sign of increase, but in some cases, made us doubt if there were not a decrease.

Briefly speaking, even in an experiment, in which an animal was bound and received cruel treatments, as in Exps. V-VIII, we must recognize the different actions of caffeine on the blood urea-nitrogen concentration according to its dosages. When a small quantity of caffeine was used, even where the diuretic effect were remarkable, the blood ureanitrogen concentration usually increased.

It has often been shown by experiments that caffeine brings out entirely opposite actions according to the quantities used. I observed myself with $A$ be $e^{4}$ in our experiment on rabbits, that the rate of blood flow and the oxygen consumption of the kidney increase when a small quantity of caffeine is injected, while a large dosage of it is fullowed, on the contrary, by a decrease of both. Wagner, ${ }^{5)}$ Leven, ${ }^{6}$ Bock, Sollmann and

4) Tashiro and A be, Tohoku Journ. Exper. Med., 1922, 3, 142.

5) Wagner, cit. by Bock in Heffter's Handb. exper. Pharmakol., Leipzig 1923 , II $-1,534$.

6) Leven, Arch. de physiol. norm. et pathol. gén., 1868, 1, 179.

7) Bock, Arch. f. exper. Pathol. u. Pharmacol., 1900, 43, 393. 
Pilcher $\mathrm{r}^{\mathrm{s}}$ have assertained that, when caffeine is given to an animal, if it is of a small quantity, the pulse rate decreses and if of a large quantity it increases, while Leven, ${ }^{6}$ Johansen, ${ }^{97}$ Bock, ${ }^{7)}$ Cushny and Naten, ${ }^{10}$ Sollmann and Pilsher ${ }^{s)}$ and others observed that the pulse rate always increases, regardless of the quantities of caffeine, when atropine is given or the vagi are previously cut.

According to these experiments, it seems that bradycardia produced by a comparatively small quantity of caffeine, is attributed to the central excitation of the vagus, but in cases where large doses are given, whether the result is caused, on the contrary, by the excitation of accelerator centres or not still appears indefinite. But we can understand this so that in cases where a little caffeine is used the urea-nitrogen concentration of the blood increases, just as the pulse rate is lessened, and in cases where large quantities of the drug are given, the blood urea-nitrogen concentration decreases as a quicker pulse is brought about.

The effect of caffeine on bluod sugar differs from that on blood ureanitrogen content, as observed in my experiments, inasmuchas the former does not differ qualitatively according to its dosage. For instance, in $\mathrm{N}$ aito and $\mathrm{Fujii}$ ' $\mathrm{s}^{11}$ experiments it was recognized that marked hyperglycaemia occurred even after a large dosis of diuretine (more than $1 \mathrm{grm}$. in the case of rabbits). Presumably, this is supposed to depend upon the tendency that the blood sugar level is raised chiefly by the excitation of the splanchnics.

\section{The Effect of Caffeine on the Blood Urea-Nitrogen Concentration of Anaesthetized Animal.}

Just as caffeine-hyperglycaemia is checked by the administration of an anaesthetic $\left(\mathrm{Bang}^{12}\right)$, so the increase of the blood urea-nitrogen concentration, caused by caffeine, should also be inhibited by an anaesthetic. If the excitation of the nervous centres coming through caffeine is a cause of increase in the blood urea-nitrogen content, this increase must be removed by the administration of an anaesthetic.

In order to decide this question, caffeine was injected into a rabbit

8) Sollm ann and Pilcher, Journ. of Pharmacol. and Exper. Therap., 1911, 3, 28.

9) Jobansen, cit. by Bock in Heffer's Handb. Exper. Pharmakol, Leipzig 1928, II-1, 534.

10) Cushny and Naten, Arch. intern. de pharmacodyn., 1901, 9, 169.

11) Naito and Fujii, Tohoku-Igaku-Zasshi, 1917, 2, 181 (Jap.).

12) Bang, Biochem. Zeitschr., 1914, 58, 236. 
under anaesthesia, the changes occurring in its blood urea-nitrogen content being examined.

Paraldehyde and urethane were used as anaesthetics, but since the latter is unsuitable for this purpose, chiefly paraldehyde (of which a detailed description was given in Part I) to the amount of about 1 c. c. per kilo body weight was administered, a dosage which brought it to a slight anaesthesia, but caused almost no change in the blood urea-nitrogen content.

Exp. IX. February 8, 1923. Rabbit $\delta$. Body weight 1.8 kilos.

\begin{tabular}{|c|c|c|c|}
\hline Time & Urea-N (mgrm \%) & $\begin{array}{l}\text { Non-protein- } \mathrm{N} \\
(\text { mgrm } ; 0)\end{array}$ & Remarks \\
\hline 925 & & & $\begin{array}{l}2 \text { c.c. paraldehyde introduced } \\
\text { into stomach. }\end{array}$ \\
\hline $10^{45}$ & 21.0 & 29.4 & \\
\hline 107 & & & $\begin{array}{l}\text { Subcutaneous injection of } 0.05 \\
\text { grm. caffeine. }\end{array}$ \\
\hline $11^{18}$ & 15.4 & 27.3 & \\
\hline $11^{4 \pi}$ & 14.0 & 27.8 & \\
\hline 100 & 15.4 & 28.0 & \\
\hline $2^{00}$ & 16.1 & 28.0 & \\
\hline $4^{00}$ & 21.7 & 28.7 & \\
\hline
\end{tabular}

Exp. X. April 13, 1923. Rabbit 3. Body weight 1.9 kilos.

\begin{tabular}{c|c|c|c}
\hline Time & Urea-N (mgrm \%ó) & $\begin{array}{c}\text { Non-protein-N } \\
\text { (mgrm } 06)\end{array}$ & Remarks \\
\hline $1^{20}$ & & & $\begin{array}{c}\text { 2 c.c. paraldehyde introduced } \\
\text { into stomach. }\end{array}$ \\
$1^{40}$ & 21.7 & 46.2 & $\begin{array}{c}\text { Subcutaneous injection of } 0.05 \\
\text { grm. caffeine }\end{array}$ \\
$1^{43}$ & 16.1 & 39.4 & \\
$2^{62}$ & 15.4 & 35.7 & \\
$2^{41}$ & 15.4 & 42.4 & \\
$3^{45}$ & 18.2 & &
\end{tabular}

In Exp. IX the blood urea-nitrogen content showed a decrease of about $29 \%$ owing to the injection of caffeine, recovering its original value in about 5 bours, and in Exp. $X$ the decrease amounted to about $30 \%$, that is to say, that the increase of the blood urea-nitrogen concentration was not only kept in check by anesthesia, but it was remarkably decreased.

This is not the case when paraldehyde is given in larger quantities, for, as described in Part I, when the anaesthesia is deepened, anaesthesia itself gives rise to a striking increase in the blood urea-nitrogen content. For instance : 
Exp. XI. March 27, 1922. Rabbit 5. Body weight 2.0 kilos.

\begin{tabular}{r|c|l}
\hline Time & Urea-N (mgrm \%) & \multicolumn{1}{|c}{ Remarks } \\
\hline $9^{50}$ & & $\begin{array}{l}\text { 4 c.c. paraldehyde introduced into stomach. } \\
11^{55}\end{array}$ \\
$11^{50}$ & 50.4 & Corneal reflex remaining. \\
$12^{10}$ & 48.7 & 0.05 grm. caffeine subcutaneously injected. \\
$12^{50}$ & 48.7 & Corneal reflex remaining. \\
$1^{50}$ & 48.7 & Corneal reflex remaining.
\end{tabular}

Exp. XII. March 21, 1922. Rabbit o. Body weight 2.1 kilos.

\begin{tabular}{r|c|l}
\hline Time & Urea-N (mgrm \%) & Remarks \\
\hline $1^{215}$ & & $\begin{array}{l}\text { 3.5 c.c. paraldehyde introduced into stomach. } \\
4^{10}\end{array}$ \\
$4^{20}$ & 44.1 & Corneal reflex remaining. \\
$4^{30}$ & 46.2 & 0.05 grm. caffeine subcutaneously injected. \\
$4^{45}$ & 46.2 & \\
$5^{20}$ & 49.0 & \\
$5^{50}$ & 51.8 & \\
$6^{50}$ & 67.2 & Corneal reflex remaining.
\end{tabular}

In these experiments, in which the anaesthesia is far deeper, the blood urea-nitrogen content before caffeine injection is far greater in comparison with that of Exps. IX and X. This may be taken as the effect of anaesthesia. With this amount of paraldehyde most of the rabbits died before they had recovered from anaesthesia. It may be added here that generally during anaesthesia the ear vessels dilated, thus making the collection of blood easy, as described in Part I, but in Exp. IX and followings, they, on the contrary, contracted after caffeine injection, more than ten minutes often being required for the collection of blood.

As to the changes of the blood urea-nitrogen concentration in Exp. XI, its decrease after the injection of caffeine was only slight; in Exp. XII it kept up a gradual increase even after the injection of caffeine until death ended it. Such changes as this may well be said to be due to the influence of anaesthesia rather than that of caffeine.

Briefly speaking, if $0.05 \mathrm{grm}$. of caffeine is given to a rabbit, which is anaesthetized with a dosage of paraldehyde, not strong enough to increase the blood urea-nitrogen concentration, the latter does not only show any increase but rather it shows a decrease. This means that the increase of the blood urea-nitrogen content caused by caffeine is arrested by paraldehyde anaesthesia. 
Since it is a well known fact that the diuretic effect of the caffeine derivatives, if these are given during anaesthesia, is greatly augmented, in my experiments the excretion of urea might be much increased through a vigorous diuresis. But the caffeine-hypercarbamidaemia, which is probably attributed to the stimulation of the central nervous system by caffeine, is most likely arrested by paraldehyde. Probably any anaesthetics, whatever they may be, will produce the effects similar to those of paraldehyde upon the increase of blood urea-nitrogen concentration due to caffeine, excepting urethane, which readily changes into urea in the animal body. In one of my experiments, the injection of $0.05 \mathrm{grm}$. caffeine during urethane anaesthesia brought about a remarkable increase in the blood urea-nitrogen concentration, while a small amount of urethane, not sufficient to cause anaesthesia, for instance, $0.5 \mathrm{grm}$. per kilo body reight, caused by it alone an apparent increase in the urea-nitrogen concentration of the blood. Further evidence demonstrating that caffeinehypercarbamidaemia is attributed to the excitement of the nervous centres is put forward by the following experiments.

\section{Action of Caffeine on the Atropinized and Vagotomized Animals.}

That when the vagus is cut off at the neck or below the diaphragm and its peripheral stump is electrically stimulated, the blood urea-nitrogen content is greatly increased, is described in Part III. On the other hand, when caffeine is given during the paraldehyde anaesthesia, hypercarbamidaemia is arrested. These evidences forced me to the assumption that excitation of the central nervous system is a cause of increased urea formation. It is highly probable, that caffeine has a tendency to stinulate the vagus centres, as it has already been demonstrated in conuection with the effect of its small dosis on the heart.

Hence my next experiment was performed in order to ascertain what changes would result in the blood urea-nitrogen content, if caffeine is administered to a rabbit atropinized beforehand. With regard to the effect of atropine on the blood urea-nitrogen concentration, Part III contains a full description. When atropine was injected into a rabbit, the blood urea-nitrogen concentration showed a tendency to derrease, but very slight.

In Exps. XIII and XIV, in which caffeine was given into a rabbit previouly atropinized, the blood urea-nitrogen concentration, which has been rery slightly decreased due to atropine, showed, through caffeine, a further decrease of about $3 \% \%$, slowly recovering 
Exp. XIII, November 28, 1922. Rabbit 3 . Body weight 1.7 kilos.

\begin{tabular}{c|c|c}
\hline Time & Urea-N (ngrm $\%$ ) & Remarks \\
\hline $1^{40}$ & 20.3 & \\
$1^{10}$ & 19.6 & 0.0005 grm. sulphuric atropine subcutaneously injected. \\
$2^{10}$ & 14.0 & 0.05 grm. caffeine subcutaneously injected. \\
$2^{20}$ & 15.4 & \\
$2^{40}$ & 19.6 & \\
$3^{10}$ & &
\end{tabular}

Exp. XIV. November 30, 1922. Rabbit 8 . Body weight 1.5 kilos.

\begin{tabular}{c|c|c}
\hline Time & Urea-N (mgrm \%) & Remarks \\
\hline $1^{01}$ & 21.7 & \\
$1^{10}$ & 18.9 & 0.0003 grm. atropine sulphate subcutaneously injected. \\
$1^{20}$ & 14.7 & 0.05 grm. caffeine subcutaneously injected. \\
$1^{30}$ & 14.7 & \\
$1^{40}$ & 18.2 & \\
$2^{30}$ & 19.6 &
\end{tabular}

Exp. XV. February 27, 1923. Rabbit 3. Body weight 2.2 kilos.

\begin{tabular}{c|c|c|c}
\hline Time & Urea-N (mgrm \%) & $\begin{array}{c}\text { Non-protein-N } \\
\text { (mgrm \%) }\end{array}$ & Remarks \\
\hline $1^{06}$ & 15.4 & 27.3 & $\begin{array}{c}0.05 \text { grm. caffeine }+0.0005 \text { grm. } \\
\text { atropine sulphate subcutan- } \\
\text { eously injected. }\end{array}$ \\
$1^{16}$ & & & \\
$1^{30}$ & 11.2 & 16.8 & \\
$1^{10}$ & 10.5 & 16.8 & \\
$2^{15}$ & 11.2 & 27.0 & \\
$3^{15}$ & 11.9 & 26.6 &
\end{tabular}

afterwards. In Exp. XV caffeine and atropine were injected at the same time, resulting in a great decrease in both urea and non-protein nitrogen concentration of the blood.

In atropinized animals, as expected, caffeine caused no increase, but rather a decrease in the blood urea-nitrogen content. This means that caffeine-hypercarbamidaemia is arrested in cases where the vagus endings are paralyzed. And the decrease in the blood urea-nitrogen content seems to be greater in the cases of atropine + caffeine than when atropine alone is given (see Part III). 
In the next place, similar experiments were performed on animals, whose vagi in the neck or in the abdomen had been severed on both sides.

Exp. XVI. December 5, 1922. Rabbit 우. Body weight 1.7 kilos.

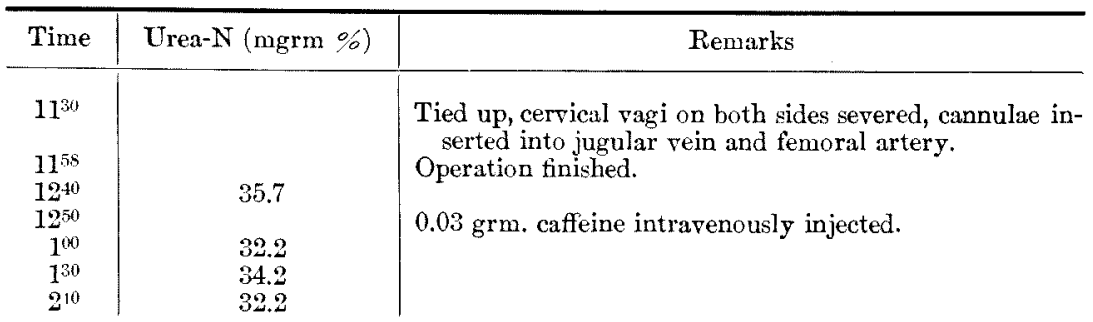

Exp. XVII. December 18, 1922. Rabbit 5. Body weight 2.0 kilos.

\begin{tabular}{c|c|c}
\hline Time & Urea-N (mgrm \%ó & Remarks \\
\hline $1^{50}$ & & $\begin{array}{l}\text { Tied up, cervical vagi on both sides severed, cannulae in- } \\
\text { serted into jugular vein and femoral artery. } \\
\text { Operation finished. }\end{array}$ \\
$2^{20}$ & & \\
$3^{100}$ & 24.5 & 0.05 grm. caffeine intravenously injected. \\
$3^{10}$ & 22.4 & \\
$3^{20}$ & 18.2 & \\
$4^{10}$ & 20.3 & \\
$5^{10}$ & 23.1 &
\end{tabular}

Exp. XVIII. December 20, 1922. Rabbit $\rho$. Body weight 2.0 kilos.

\begin{tabular}{c|c|l}
\hline Time & Urea-N (mgrm 00$)$ & \multicolumn{1}{|c}{ Remarks } \\
\hline $2^{50}$ & & $\begin{array}{l}\text { Tied up, vagi severed below diaphragm, cannulae in- } \\
\text { serted into jugular vein and femoral artery. } \\
\text { Operation finished. }\end{array}$ \\
$3^{12}$ & & \\
$4^{00}$ & 26.6 & 0.05 grm. caffeine intravenously injected. \\
$4^{10}$ & & \\
$4^{20}$ & 26.6 & \\
$4^{10}$ & 25.9 & \\
$5^{10}$ & 25.1 & Died. \\
$6^{10}$ & 25.9 &
\end{tabular}

Exp. XIX. Rabbit $\hat{\sigma}$. December 18, 1922, abdominal vagi severed and December 26, 1922, experiment performed. Body weight 1.5 kilos.

\begin{tabular}{l|c|c}
\hline Time & Urea-N (mgrm \% $)$ & Remarks \\
\hline $2^{00}$ & 17.5 & \\
$2^{10}$ & & 0.05 grm. caffeine subcutaneously injected. \\
$2^{30}$ & 14.7 & \\
$3^{10}$ & 15.4 & \\
$4^{10}$ & 15.4 & \\
$5^{10}$ & 16.8 &
\end{tabular}


Exp. XX. Rabbit 3 . December 11, 1922, abdominal vagi severed and January 26, 1923, experiment performed. Body weight 2.0 kilos.

\begin{tabular}{c|c|c}
\hline Time & Urea-N (mgrm \%) & Remarks \\
\hline $10^{45}$ & 25.2 & \\
$10^{47}$ & 24.5 & 0.05 grm. caffeine subcutaneously injected. \\
$11^{10}$ & 23.8 & \\
$11^{20}$ & 23.8 & \\
$11^{45}$ & 25.9 & \\
$1^{20}$ & &
\end{tabular}

In Exps. XVI and XVII, caffeine was injected soon after the vagi on both sides in the neck were cut, showing a slight decrease of the blood urea-nitrogen content in each experiment.

In Exp. XVIII, the vagi were severed right below the diaphragm. Following the injection of caffeine, which occurred soon after the laparotomy, the blood urea-nitrogen value showed no significant changes, its decrease being only slight and not going very far over the limit of technical error.

In cases where an experiment is taken up directly after the laparotomy some unexpected and surprising results are of ten brought about that come through an unknown cause. Exps. XIX and XX were performed for this reason. These were made several days after the abdominal vagi were aseptically cut and left waiting the healing of the operation. Exp. XIX was made nine days after the operation and Exp. XX thirty-seven days after. In both cases the blood urea-nitrogen ralue was very slightly decreased after the injection of caffeine.

From these experiments given above it may be learned, that even if caffeine is injected into a rabbit with its vagi previously severed, the blood urea-nitrogen concentration does not only increase but shows rather a tendency to decrease, more or less. From the results of experiments with paraldehyde + caffeine and with atropine + caffeine as well as experiments just above described, we can safely infer that caffeine-hypercarbamidaemia is caused by the stimulation of the vagus centres.

According to Anten's $s^{2}$ experiment, in a dog, the diuretic effect of caffeine is not manifest, while in an animal with its renal vagi cut or with atropine given, the effect seems to be striking. Caffeine should show a diuretic effect not only in normal, but also in atropinized or vagotomized rabbits. That in thus treated animals the administration of caffeine is not followed by an increase of the blood urea-nitrogen concentration but ratber by a decrease, is due probably to the facts that the increased formation of urea, coming through caffeine, is arrested, owing to the weakening or abolition of the vagus tonicity besides lessening the blood urea-nitrogen content, more or less, by atropine itself, on the other hand, also to the increased 
elimination of urea resulting from the angmented output of urine. In this case the excitation of the sympathetic centres through caffeine may also be taken into account. In my experience, the blood urea-nitrogen content has a tendency to decrease at the time of the injection of adrenaline or of the stimulation of the splanchnics.

The decrease in the blood urea-nitrogen concentration, when caffeine is injected into an atropinized animal, seems to surpass the effect of caffeine in vagotomized animals, an evidence that can not be passed over as a mere incident, but the causal investigation of which is a matter of difficulty.

The reason why the blood urea-nitrogen content decreases when a comparatively large amount of caffeine is administered is hard to dispute. The excitation of the sympathetic centres, which is significantly exhibited in case of such doses of caffeine, is most likely one of the reasons.

\section{Conclusions.}

1. A small dose of caffeine $(0.05 \mathrm{grm}$. $)$ increases the blood urea-nitrogen concentration in a rabbit.

2. The increase of the blood urea-nitrogen content caused by caffeine is not only arrested, but rather turns to decrease, by paraldehyde.

3. The blood urea-nitrogen content is not augmented by caffeine in atropinized or vagotomized rabbits, it is rather lessened.

Caffeine-hypercarbamidaemia is caused by the stimulation of the vagus centres.

4. A large dosage of caffeine gives rise to the decrease of the blood urea-nitrogen concentration. 